\title{
A study of food fads and overweight in adolescents from an urban area
}

\author{
Randhir V. Dhobale ${ }^{1 *}$, Suhas G. Kumbhar ${ }^{2}$, Alka D. Gore ${ }^{1}$, Vivek B. Waghachavare ${ }^{1}$, \\ Yugantara R. Kadam ${ }^{1}$, Girish B. Dhumale ${ }^{1}$
}

\begin{abstract}
${ }^{1}$ Department of Community Medicine, Bharati Vidyapeeth Deemed University Medical College and Hospital, Sangli, Maharashtra, India

${ }^{2}$ Department of Pediatrics, Bharati Vidyapeeth Deemed University Medical College and Hospital, Sangli, Maharashtra, India
\end{abstract}

Received: 23 February 2016

Received: 25 February 2016

Accepted: 02 March 2016

\section{*Correspondence:}

Dr. Randhir V. Dhobale,

E-mail: dr.randhirdhobale@gmail.com

Copyright: ( ) the author(s), publisher and licensee Medip Academy. This is an open-access article distributed under the terms of the Creative Commons Attribution Non-Commercial License, which permits unrestricted non-commercial use, distribution, and reproduction in any medium, provided the original work is properly cited.

\section{ABSTRACT}

Background: Faulty dietary habits in modern era hamper the nutritional health of adolescents. Trend of consuming fast food have worse effect on children and youth often more than adults. This is because most of the fast foods are targeted towards children and there is a sustained pattern of eating fast foods and eating out. The objective of the study was to study the association between fast food consumption and development of overweight in adolescents from an urban area.

Methods: This is a cross-sectional study. 1500 students from $5^{\text {th }}-10^{\text {th }}$ class schools from urban area of Sangli-MirajKupwad Municipal corporation area were selected for study. A study period was from July 2012-Sept 2014. Predesigned and pretested questionnaire were used as study tools. Statistical analysis was done by using Chi-square test.

Results: Among the 1500 children, overweight was seen more in boys, belonging to age group of 17 years and children living in nuclear families. The significant association was found between overweight \& children consuming fast food always. Total $9.2 \%$ children found overweight.

Conclusions: Increase consumption of dry snacks and fast food hamper the nutritional status of adolescents and may lead to overweight.

Keywords: Fast foods, Overweight, Adolescents, Body mass index

\section{INTRODUCTION}

Adolescents represent around $20 \%$ of the global world population and around $84 \%$ of them are found in developing countries. ${ }^{1}$ Adolescence is a period, which forms the base of future health and social life. The health problems and habits acquired during this phase prove a lifelong hindrance in well-being.

Fast food culture is an emerging trend among the younger generation. The ready availability of fast food, its taste, low cost, marketing strategies and peer pressure make them popular with children and adolescents. Trend of consuming fast food has worse effect on children and youth often more than adults. This is because most of the fast foods are targeted towards children and there is a sustained pattern of eating fast foods and eating out., Faulty dietary habits in modern era hamper the nutritional health of adolescents.

Dietary patterns that include a higher intake of fruits and vegetables, which are good sources of complex carbohydrates, vitamins, and minerals, are associated with a decreased risk for obesity. ${ }^{4}$ Children and adolescents tend to consume low quantities of fruits and vegetables and to have a high intake of fast foods and 
carbonated drinks. Being overweight and obese increases the risk of development of conditions such as hypertension, diabetes mellitus, coronary artery disease, osteoarthritis and certain types of cancer. ${ }^{5}$

Most adolescents consume diets that are higher in fat and lower in fruits and vegetables than recommended. ${ }^{6}$

The problem of food fads and its resultant health issues, like overweight are amply highlighted in the western literature. However such studies from India are few and concentrated in metropolitan area.

Hence we planned the current study to investigate the magnitude of food fads and overweight in the nonmetropolitan urban area of Sangli district, Maharashtra. We also planned to study the association between fast food consumption and development of overweight in adolescents.

\section{METHODS}

This was a cross-sectional study conducted in government and private, aided and unaided, co-education schools from Sangli-Miraj-Kupwad corporation area of Sangli city in Western Maharashtra. It was undertaken after Institutional Ethical Committee approval and permission from respective authorities. Consent was obtained from the parents and then the students were given a brief orientation regarding proforma and explained the purpose of the study. The study population was early adolescent school going children studying in classes $\mathrm{V}^{\text {th }}-\mathrm{X}^{\text {th }}$. The schools were chosen by simple random sampling with lottery method and then information from all students of the selected school was taken i.e. by using cluster random sampling method Sample size calculated by using the statistical formula, was 359 for each of 4 groups, like private unaided English school, private unaided Marathi school, corporation school and private aided school. Total sample size derived was 1500 . The study duration was July 2012Sep 2014.

Study tool was a self-administered questionnaire, with good validity and reliability. It was developed in English and Marathi; with the help of published literature, language and subject experts. The questionnaire consists of general information like name, age, sex, address, class; nutritional assessment such as type of diet, frequency of fast food, consumption of cold drinks etc.

The criterion for Overweight is taken as: Children having BMI $>85^{\text {th }}$ percentile of weight for age as per the WHO child growth standards, 2006. ${ }^{7}$ WHO has recommended various indices based on anthropometry to evaluate the nutritional status of the school children. BMI was used for assessment of nutritional status i.e. overweight among adolescents. $^{8}$

Analysis was done using SPSS 22 and Microsoft Excel 2007. Proportion, percentages, chi square test and multivariate analysis were applied.

\section{RESULTS}

The total students examined in the study were 1500; out of which $901(60.06 \%)$ were boys and remaining 599 $(39.93 \%)$ girls. The number of boys was significantly higher. The information of students was collected according to their socio-economic variables and various food items; by giving questionnaire to them. Range of age of students was 10-17 years and the mean \pm SD was 12.7 \pm 1.79 . Mean BMI of students was 17.01 ( $\mathrm{SD} \pm 4.36)$.

Association of overweight with some of the sociodemographic characters, like age, gender and type of family was assessed as shown in Table 1. Overweight was noted in $102(10.1 \%)$ children less than 14 years of age group; whereas $40(8.2 \%)$ children more than 14 years of age show overweight. The prevalence of overweight was seen more in boys $96(10.7 \%)$ as compared to girls $46(07.7 \%)$.

Out of 1500 children, $703(46.86 \%)$ children were living in joint families \& $797(53.13 \%)$ in nuclear families. Children living in nuclear families found to be more overweight $86(10.8 \%)$.

Table 1: Association of socio-demographic variables with overweight.

\begin{tabular}{|c|c|c|c|c|c|}
\hline \multirow{2}{*}{ Variables } & & \multicolumn{2}{|l|}{ Overweight } & \multirow{2}{*}{ Total } & \multirow{2}{*}{ Significance } \\
\hline & & Absent & Present & & \\
\hline \multirow{2}{*}{ Age group } & $<14$ & $908(89.90 \%)$ & $102(10.10 \%)$ & $1010(100 \%)$ & \multirow{2}{*}{$\chi^{2}=1.443, p=0.229$} \\
\hline & $>=14$ & $450(91.80 \%)$ & $40(8.20 \%)$ & $490(100 \%)$ & \\
\hline \multirow{2}{*}{ Gender } & Boys & $805(89.30 \%)$ & $96(10.70 \%)$ & $901(100 \%)$ & \multirow{2}{*}{$\chi^{2}=3.717, p=0.053$} \\
\hline & Girls & $553(92.30 \%)$ & $46(7.70 \%)$ & $599(100 \%)$ & \\
\hline \multirow{2}{*}{ Family type } & Joint & $647(92 \%)$ & $56(8 \%)$ & $703(100 \%)$ & \multirow{2}{*}{$\chi^{2}=3.477, p=0.062$} \\
\hline & Nuclear & $711(89.20 \%)$ & $86(10.80 \%)$ & $797(100 \%)$ & \\
\hline Total & & $1358(90.50 \%)$ & $142(9.50 \%)$ & $1500(100 \%)$ & \\
\hline
\end{tabular}


Table 2: Association between various food items with overweight.

\begin{tabular}{|c|c|c|c|c|c|}
\hline \multirow{2}{*}{ Variables } & & \multicolumn{2}{|c|}{ Overweight } & \multirow{2}{*}{ Total } & \multirow{2}{*}{ Chi-square } \\
\hline & & Absent & Present & & \\
\hline \multirow{4}{*}{ Dry snacks } & \multirow{2}{*}{ Rare } & 341 & 28 & 369 & \multirow{4}{*}{$\begin{array}{l}\chi^{2}=2.015 \\
P=0.156\end{array}$} \\
\hline & & $92.40 \%$ & $7.60 \%$ & $100.00 \%$ & \\
\hline & \multirow{2}{*}{ Always } & 1017 & 114 & 1131 & \\
\hline & & $89.90 \%$ & $10.10 \%$ & $100.00 \%$ & \\
\hline \multirow{4}{*}{ Bakery products } & \multirow{2}{*}{ Rare } & 256 & 25 & 281 & \multirow{4}{*}{$\begin{array}{l}\chi^{2}=0.131 \\
P=0.717\end{array}$} \\
\hline & & $91.10 \%$ & $8.90 \%$ & $100.00 \%$ & \\
\hline & \multirow{2}{*}{ Always } & 1102 & 117 & 1219 & \\
\hline & & $90.40 \%$ & $9.60 \%$ & $100.00 \%$ & \\
\hline \multirow{4}{*}{ Non veg food } & \multirow{2}{*}{ Rare } & 572 & 47 & 619 & \multirow{4}{*}{$\begin{array}{l}\chi^{2}=4.318 \\
P=0.038\end{array}$} \\
\hline & & $92.40 \%$ & $7.60 \%$ & $100.00 \%$ & \\
\hline & \multirow{2}{*}{ Always } & 786 & 95 & 881 & \\
\hline & & $89.20 \%$ & $10.80 \%$ & $100.00 \%$ & \\
\hline \multirow{4}{*}{ Samosa \& other fried foods } & \multirow{2}{*}{ Rare } & 358 & 32 & 390 & \multirow{4}{*}{$\begin{array}{l}\chi^{2}=0.979 \\
P=0.323\end{array}$} \\
\hline & & $91.80 \%$ & $8.20 \%$ & $100.00 \%$ & \\
\hline & \multirow{2}{*}{ Always } & 1000 & 110 & 1110 & \\
\hline & & $90.10 \%$ & $9.90 \%$ & $100.00 \%$ & \\
\hline \multirow{4}{*}{ Pizza, burger etc } & \multirow{2}{*}{ Rare } & 923 & 92 & 1015 & \multirow{4}{*}{$\begin{array}{l}\chi^{2}=0.594 \\
\mathrm{P}=0.441\end{array}$} \\
\hline & & $90.90 \%$ & $9.10 \%$ & $100.00 \%$ & \\
\hline & \multirow{2}{*}{ Always } & 435 & 50 & 485 & \\
\hline & & $89.70 \%$ & $10.30 \%$ & $100.00 \%$ & \\
\hline \multirow{4}{*}{ Carbonated Drinks } & \multirow{2}{*}{ Rare } & 751 & 68 & 819 & \multirow{4}{*}{$\begin{array}{l}\chi^{2}=2.851 \\
P=0.091\end{array}$} \\
\hline & & $91.70 \%$ & $8.30 \%$ & $100.00 \%$ & \\
\hline & \multirow{2}{*}{ Always } & 607 & 74 & 681 & \\
\hline & & $89.10 \%$ & $10.90 \%$ & $100.00 \%$ & \\
\hline \multirow{2}{*}{ Total } & & 1358 & 142 & 1500 & \\
\hline & & $90.50 \%$ & $9.50 \%$ & $100.00 \%$ & \\
\hline
\end{tabular}

Table 3: Binary logistic regression model-association of various variables with overweight.

\begin{tabular}{|lllllllll|}
\hline Variables & B & S.E. & Wald & df & Sig. & OR & \multicolumn{2}{c|}{ 95\% C.I. for OR } \\
\hline Gender & -0.397 & 0.189 & 4.429 & 1 & 0.035 & 0.672 & 0.464 & 0.973 \\
\hline Family type & -0.372 & 0.182 & 4.170 & 1 & 0.041 & 0.689 & 0.482 & 0.985 \\
\hline Cold drink & -1.082 & 0.596 & 3.299 & 1 & 0.069 & 0.339 & 0.105 & 1.089 \\
\hline Age & -0.292 & 0.197 & 2.195 & 1 & 0.138 & 0.746 & 0.507 & 1.099 \\
\hline Constant & -0.049 & 0.726 & 0.005 & 1 & 0.946 & 0.952 & & \\
\hline \multicolumn{2}{l}{ B= Regression coefficient, SE=Standard error, OR=Odds ratio, CI=Confidence interval } & &
\end{tabular}

Table 2 shows association between various food items with overweight. These food items are like dry snacks, bakery products, non-vegetarian food, samosa, pizza and carbonated drinks. Frequency of eating these food items was considered on the basis of daily or occasionally eating. Overweight is computed as per various food items they consume. The children who consume these food items always shows more overweight as compared to children consume it rarely. Overweight was observed significantly more in $95(10.8 \%)$ children who always consume non-veg food items $(\mathrm{p}=0.038)$, whereas for the other food items, this association was not significant.

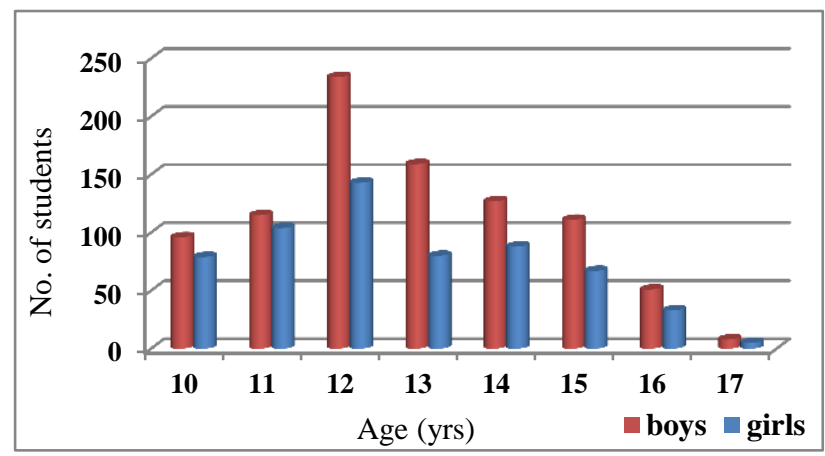

Figure 1: Age-sex distribution of students. 
Binary logistic regression was applied with Wald's backward method, where over weight was considered as dependent variable and different socio-demographic factors as well as various food items as independent variables. Chance accuracy of the model is 90.5 . Gender $(p=0.035)$ and type of family $(p=0.041)$ were the best predictors for overweight (Table 3 ).

\section{DISCUSSION}

There is an increasing trend of consumption of energydense foods, i.e. fast food, which is high in fat, sugar, salt and oil, seen in children. Fast food is easily available, yummy in taste and cheaper at cost; most of children attracted towards these food fads. These types of eating food habits causes overweight, which further leads to various health problems.

In our study, overweight decreases as age increases. It is more in school children whose age is less than 14 years of age. A study done by Kumar S et al showed, the prevalence of overweight increased with increasing age. 9 Raj $M$ et al in their study showed that there was increasing trend of BMI along with age in both sexes. ${ }^{10}$

Overweight was seen more in boys than girls, but not statistically significant. The reason may be gender discrimination as females were often neglected and boys were exposed often outside home and easily accessible towards fast food and junk food. Similar study done by Anuradha RK et al in Tirupati town of Andhra Pradesh, India, shown that about $11.2 \%$ of the boys and $10.3 \%$ of the girls were overweight. ${ }^{11}$

$86(10.8 \%)$ children from nuclear families found to be overweight as compared to children in joint families. There are chances that the child's nutritional diet may be neglected in the nuclear family, if mother and father both are busy in their jobs; whereas this may not happen with the children living in joint families. Similar results were also noted by Parrika et al. ${ }^{12}$

We have studied various food items that are generally consumed by school children and these are available in and around the schools.

Now days, dry snacks are easily available around schools at affordable price and children are easily attracted. Consuming dry snacks and bakery products frequently along with regular diet may increase their weight and BMI status. Even eating dry snacks along with watching television leads to overweight and obesity in children.

Various non-vegetarian food items like mutton, chicken, eggs were generally consumed by school children. Some of children may eat them frequently. Frequent eating of non-vegetarian food items in children may lead to overweight. Aggarwal $\mathrm{T}$ et al done study in affluent adolescents from Ludhiana, Punjab found that $82.3 \%$ children were non-vegetarian and $8.8 \%$ vegetarians were obese. ${ }^{13}$ Meat intake has been found to be associated with obesity and its cardiovascular complications. Children in Switzerland showed a direct association between intake of meat products and overweight. In Rome, obesity was found to be significantly associated with hypertension, and hypertensive school children had a higher intake of meat and eggs in their diet. ${ }^{14}$

Children who always consume fried foods like samosa, kachori, alu wada, manchurian etc. found to be more overweight. Fried foods are easily available on the streets, bakery, out lets in molls and even in restaurants. When they eat along with regular meals, it affects their nutritional status. A study done by Amin TT et al showed that frequent consumption of fast foods, low servings per day of fruits and vegetables were all predictors of obesity and overweight among the school children studied. ${ }^{15}$

Generally, children are attracted to junk food like pizza and eating in large amounts may result in over nutrition in children. The children who consume cold drinks always were more overweight. Ludwig DS, et al and For Shee et al noted that middle-school children who consumed more carbonated soft drinks were more likely to become at risk of overweight. ${ }^{16,17}$ Moreover, the reasons for consuming larger than average amounts of these beverages should be explored, especially among children and adolescents who are engaged in strenuous physical activity. The current study reflected these findings.

\section{CONCLUSION}

Increase consumption of dry snacks and fast food hamper the nutritional status of adolescents and may lead to overweight.

\section{Funding: No funding sources \\ Conflict of interest: None declared \\ Ethical approval: The study was approved by the Institutional Ethics Committee}

\section{REFERENCES}

1. Dasgupta A, Butt A, Saha TK, Basu G, Chattopadhyay A, Mukherjee A. Assessment of nutrition in adolescents: can BMI be replaced by MUAC. Indian J Comm Med. 2010;35:276-99.

2. Story M, Neumark-Sztainer D, French S. Individual and environmental influences on adolescent eating behaviours. J Am Diet Assoc. 2002;102:S40.

3. Rydell SA, Harnack LJ, Oakes JM. Why eat at fastfood restaurants: reported reasons among frequent consumers. J Am Diet Assoc. 2008;108:2066.

4. Neumark-Sztainer D, Story M, Resnick MD, Blum RW. Correlates of inadequate fruit and vegetable consumption among adolescents. Prev Med. 1996;25:497-505.

5. Galhotra A, Abrol A, Agarwal N, Goel NK, Gupta S. Life style related risk factors for cardiovascular 
diseases in Indian adolescents. Intern $\mathbf{J}$ Health. 2009;9.

6. Troiano RP, Briefel RR, Carroll MD, Bialostosky $\mathrm{K}$. Energy and fat intake of children and adolescents in the United States. Data from the national health and nutrition examination surveys. Am J Clin Nutr. 2000;72:1343-53.

7. WHO, WHO child growth standards, length/heightfor-age, weight-for-age, weight-for-length, weightfor height and body mass index-for age, methods and development. 2006.

8. Bailey KV, Ferro-Luzzi A. Use of body mass index of adults in assessing individual and community nutritional status. Bull World Health Organization. 1995;73:673-80.

9. Kumar S, Mahabalaraju DK, Anuroopa MS. Prevalence of obesity and its influencing factor among affluent school children of Davangere City. Indian J Comm Med. 2007;32:1.

10. Raj M, Sundaram KR, Paul M, Deepa AS, Kumar RK. Obesity in Indian children: time trends and relationship with hypertension. Nat Med J India. 2007;20:288-93.

11. Anuradha RK, Sathyavathi RB, Reddy TM, Hemalatha R, Sudhakar G, Geetha P et al. Effect of social and environmental determinants on overweight and obesity prevalence among adolescent school children. Indian $\mathrm{J}$ Endocrinol Metab. 2015;19:283-7.

12. Parrika S, Maki P, Levalahti E, Lehtinen-Jacks S, Marte OT, Laatikainen T. Associations between parental BMI, socioeconomic factors, family structure and overweight in Finnish children: a path model approach BMC Public Health. 2015;15:271.

13. Aggarwal T, Bhatia RC, Singh D, Sobti PC. Prevalence of obesity and overweight in affluent adolescents from Ludhiana, Punjab. Indian Pediatr. 2008;45:500-01.

14. Warraich HJ, Javed F, Faraz-ul-Haq M, Khawaja FB, Saleem S. Prevalence of obesity in school going children of Karachi. PLoS One. 2009;4:e 4816.

15. Amin TT, Al-Sultan AI, Ali A. Overweight and Obesity and their association with dietary habits, and sociodemo graphic characteristics among male primary school children in Al-Hassa, kingdom of Saudi Arabia. Indian J Community Med. 2008;33:172-81.

16. Ludwig DS, Peterson KE, Gortmaker SL. Relation between consumption of sugar-sweetened drinks and childhood obesity: a prospective, observational analysis. Lancet. 2001;357:505-8.

17. Forshee RA, Anderson PA, Storey ML. Total beverage consumption and beverage choices among children and adolescents. Intern J Food Sci Nutrit. 2006;54:297-307.

Cite this article as: Dhobale RV, Kumbhar SG, Gore AD, Waghachavare VB, Kadam YR, Dhumale GB. A study of food fads and overweight in adolescents from an urban area. Int J Community Med Public Health 2016;3:813-7. 